\title{
American Journal of
} \section{Health, Medicine and Nursing Practice}

(AJHMN)

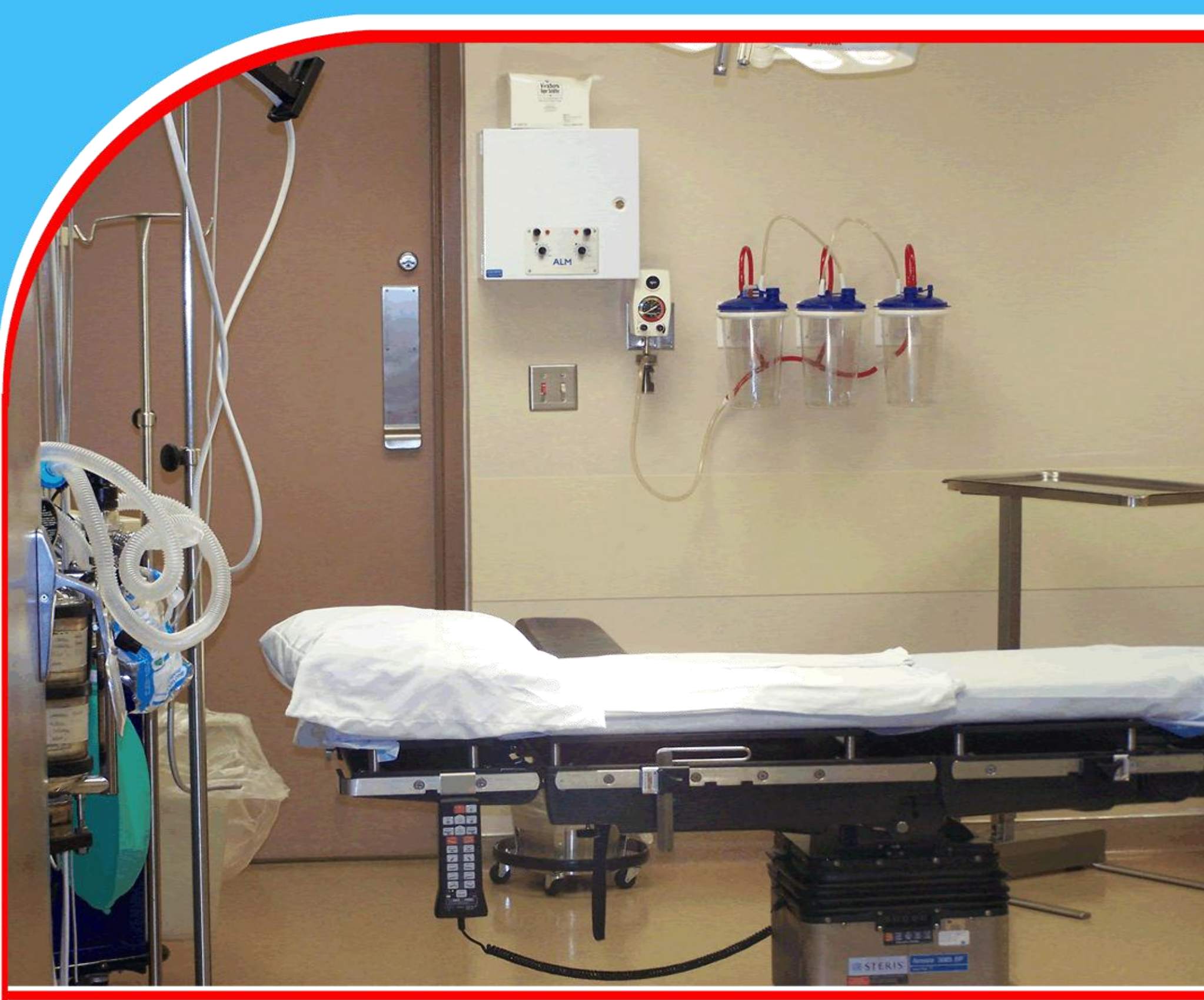

ASSESSMENT OF OCCUPATIONAL HEALTH RISK AND AWARENESS OF SCAVENGERS TO COVID-19 IN ABUJA MUNICIPAL AREA COUNCIL, NIGERIA 


\title{
ASSESSMENT OF OCCUPATIONAL HEALTH RISK AND AWARENESS OF SCAVENGERS TO COVID-19 IN ABUJA MUNICIPAL AREA COUNCIL, NIGERIA.
}

\author{
Oyelayo, A. Adekiya \\ Department of Geography and Environmental Management \\ Faculty of Social Sciences \\ University of Abuja \\ Corresponding Author's Email: oyelayoadekiya@gmail.com
}

\begin{abstract}
Purpose: The aim of this study was to evaluate the occupational health risk of scavengers and their awareness to covid-19 in Abuja Municipal Area Council of the FCT a view to acknowledge the vulnerability of scavengers in the pandemic and how they simultaneously pose a threat to the general public.

Methodology: A descriptive survey research was employed for the study. The population consisted of 277 scavengers, from 12 sites in Abuja Municipal Area Council. The instrument used for this study was a structured questionnaire. The questionnaire was divided into five sections. The first section collected information on socioeconomic characteristics of scavengers. The second section collected information on awareness on Covid 19 and sources of information. The third section was on use of safety tools and hygiene practices of scavengers. The forth section was on occupational injuries and diseases associated with scavenging and the fifth section was on measures taken to reduce health effects of scavenging. The questionnaire was interviewadministered to the scavengers.

Findings: The study revealed that $82.6 \%$ of scavengers believe in the existence of Covid-19 pandemic. About 58.4\% do no use hand gloves and $64.6 \%$ do not wear boots during work. Majority $(90 \%)$ of scavengers have sustained injuries from glass and sharp objects and about 71 $\%$ form nails .Occupational disease associated with scavenging include skin rash and (83.4\%), back pain, (71.6\%), chest pain, (61.4\%), Diarrhoeal ( $56.5 \%$ and cough (45.20\%). Majority (80.7 $\%$ ) of the scavengers were not prepared to change their jobs, only about $30.4 \%$ of them were prepared to purchase and use personal protective equipment as a measure to reduce occupational injury and diseases. About $53.9 \%$ of them use illicit drugs (mainly marijuana) to overcome the stress of the job.

Recommendations: The study, recommend that scavenging be legalized, so that the government and nongovernmental organizations can help in educating the scavengers on the importance of personal hygiene and personal protective equipment in reducing occupational injuries and diseases.
\end{abstract}

Key words: Diseases, Injuries, Personal Protective Equipment (PPE), Public and Waste. 


\section{INTRODUCTION}

The International Labour Organization (2004) defines Scavenging as manual sorting and picking of recyclables/reusable materials from mixed waste at legal and illegal landfills, dumpsites, street bins and piles, transfer points as well as waste collection trucks. A scavenger is a person who salvages reusable or recyclables to sell or for personal consumption (Owusu-Sekyere, 2014). In this role, scavengers are mediators in the relationship between societies and their environment (Downs and Medina, 2000) Scavenging from waste reduces waste reaching the landfill site and also provide jobs for the urban poor.

It is an economic activity that provides income for over 15 million people worldwide (Medina 2010). Kashyap and Visvanathan (2014) noted that up to $2 \%$ of the population in African, Asian and Latin American cities lives on scavenging income. Scavengers are important players with a very positive and important role in waste management sector of developing countries (Yahaya, 2018). In Nigeria, scavenging is a source of income and employment generation for the youth. It is also a source of raw material of the construction industry, bottling plants and plastic manufacturers (Asibor \& Edjere, 2017).

Solid waste management is a major concern in many urban centres in Nigeria. Nigeria generates more than 32 million tons of solid waste annually, out of which $20-30 \%$ is collected (Bakare, 2016). Due to lack of sufficient funds, enough labour, vehicles and expertise, the waste management agency is not able to effectively manage waste in many cities in Nigeria. The waste disposal option in many cities is predominantly open dumping. The Abuja Environmental Protection Board (AEPB) which is responsible for solid waste management in Abuja, have no formal recycling programme or strategy for the city of Abuja. No material recovery facility exists in the city either. As such materials re-use and recycling activities throughout the municipality is limited to household re-use and scavenging activities of the urban poor (Ezeah, Roberts, Phillips, Mbeng \& Nzeabibe 2014)

Scavengers, carry large plastic sack and use bare hands or sometimes iron hook to rummage materials through the waste dumps sites to recover or salvage valuable discarded materials such as scrap metals, plastics, bottles, paper, electronic and electrical equipment, household furniture, textile material, wood, construction and demolition wastes and sometimes food. These reusable or recyclables materials are then sold to wholesale buyers.

Despite their vital role in solid waste management, scavengers are generally socially marginalized, they live and work without basic economic and social security, under conditions which are extremely hazardous to health and detrimental to family, social and educational development (Oyelola, Babatunde, Abiodun and Popoola 2018) Scavengers are exposed to a number of health hazards and suffer injuries as they rummage materials through the waste dumpsites. Over the past months, with the present of novel coronavirus pandemic in Nigeria, scavengers are at huge risk. This is because in Nigeria, healthcare waste is collected and disposed in conjunction with normal domestic/household waste in open dumpsites. (Ebisike, 2010; Adekiya \& Anokwu, 2020).

Sifting through the rubbish with bare hands, scavengers are exposed daily to Covid-19 disease through hazardous waste. These hazardous waste comprises of coronavirus test kits, face masks, 
hand gloves, medical dressing stained with blood and pus, etc. Covid-19 disease has presently infected 104 million people globally and claimed over 2 million lives.

It is against this background that this study aimed at evaluating the occupational health risk of scavengers and their awareness to covid-19 in Abuja Municipal Area Council. This is with, a view to acknowledge the vulnerability of scavengers in the pandemic and how they simultaneously pose a threat to the general public.

\section{LITERAURE REVIEW}

\section{The Practice of Scavenging}

Scavenging and recycling activities have existed for millennia. In Africa, it is believed that early hominids scavenged in order to complement their diet, especially during the dry season, when plant food were most scarce. The risk associated with hunting was also avoided by scavenging for animal meat killed by predators or dead from natural causes (Blumenschine \& Cavallo, 1992). Archaeological evidence have also suggested that metal scraps and metallic objects no longer useful may have been melted and recycled as early as 3000 BC (Downs \& Medina, 2000). Throughout the medieval and renaissance periods in Europe and America, scavengers played a crucial role in papermaking by supplying rags to the paper mills for nearly 1,000 years. Artisans in medieval Europe collected urine and dog excrement for industrial purpose and used them to make saltpeter (potassium nitrate). Human excrement also provided fertilizer for backyard gardens and household garbage was fed to pigs (Downs \& Medina, 2000).

In the nineteenth century, urbanization and industrialization played major roles in the development of scavenging and recycling activities. At this time scavenging acquired the meaning of cleaning out, street sweeping, cleansing rivers and refuse collection. Other names for scavenging were known as "rag and bone men", "totters" and "rag pickers" (Furedy, 1984). Statistics compiled at the end of the nineteenth century showed that the scavenging team performed the bulk of refuse collection in many U.S cities. In Boston in 1890 for example, scavenging team collected approximately 350,000 loads of household waste, ashes and street sweeping. In Manhattan, scavenging team collected an average of 612 tons of waste daily (American Public Works Association, 1976). From the 1950s, the trade in bones, bottle etc. diminished gradually in the developed countries. In America however, scavenging continue to exist among the poor and homeless, who recover materials from waste for reuse or recycling. Scavengers also recover food to eat from restaurants waste, form dumpsters at grocery stores, discarded clothes for reuse and recyclable items as books and reparable appliances for sale (Downs \& Medina, 2000). In developing countries, scavenging plays an important role in supplying raw materials to industry and represent a common survival strategy for the poor. Since most of the third world countries, usually lack recycling programs, the bulk of recycling activities are carried out informally by scavengers (Bartone, 1988).

\section{Economic impact of Scavenging}

Scavenging contributes to reduce the amount of solid waste to be disposed, it contribute to preservation of natural resources by diverting waste from dumpsites back to material cycle. It provides income to unemployed individuals, supply inexpensive raw materials to industries and 
reduce the demand for collection, transport and disposal equipment and facilities (Asibor \& Edjere, 2017; Yahaya, 2018)

\section{Occupational Health Hazard of Scavenging}

Scavengers are exposed to numerous hazards: such as infectious waste from hospitals, smoke and fumes from burning waste feces, contaminated needles, toxic paper, heavy metals from batteries, bottles, chemical waste containers and harsh weather conditions. In addition, scavengers spend most of the time working in a bent position as such, scavengers suffer from chronic backache (AlKhatib, Al-Sari \& Kontogianni 2020).

Scavengers are vulnerable to three major health risks: accidents, infection, and chronic diseases. Accidents could lead to injury or death and this could be caused by heavy equipment, fire outbreaks, falling from heights and buried in the waste. Infections is caused by direct contact with infectious waste, bites from dogs (with threat of rabies), and enteric infections transmitted by insects feeding on waste. Chronic diseases such as respiratory diseases is caused from exposure to dust and toxic compounds. Cardiovascular disorders, and heat stress due to exposure to excessive temperature, and hearing function loss result from exposure to excessive noise. Hazardous health care waste also exposes scavengers to human immune deficiency virus (HIV) and hepatitis infection. (Gutberlet \& Baeder 2008; Aboagye-Larbi, Acheampong \& Carboo 2014; Jajulwar, Saji \& Suryawanshi 2017; Al-Khatib et al 2020).

\section{THE STUDY AREA}

The Federal Capital Territory (FCT) was created in1976, it is 1,100kilometres away from Lagos. It is located in the heartland of the country. It lies between latitude $8^{0} 25^{\prime \prime}$ and $9^{0} 21^{\prime \prime}$ north of the equator and longitude $6^{0} 45^{\prime \prime}$ and $7^{0} 39^{\prime \prime}$ east of the Greenwich meridian. Its area of land coverage is $8,000 \mathrm{~km}^{2}$. The Federal Capital Territory is divided into six area councils namely: Abaji, Kwali, Kuje, Bwari, Gwagwalada and Abuja Municipal Area Council (AMAC). The AMAC which is the study area, has an estimated land of $1,769 \mathrm{~km}^{2}$. The projected population of AMAC is estimated to 3.2 million (Federal Capital Development Authority, 2017). 


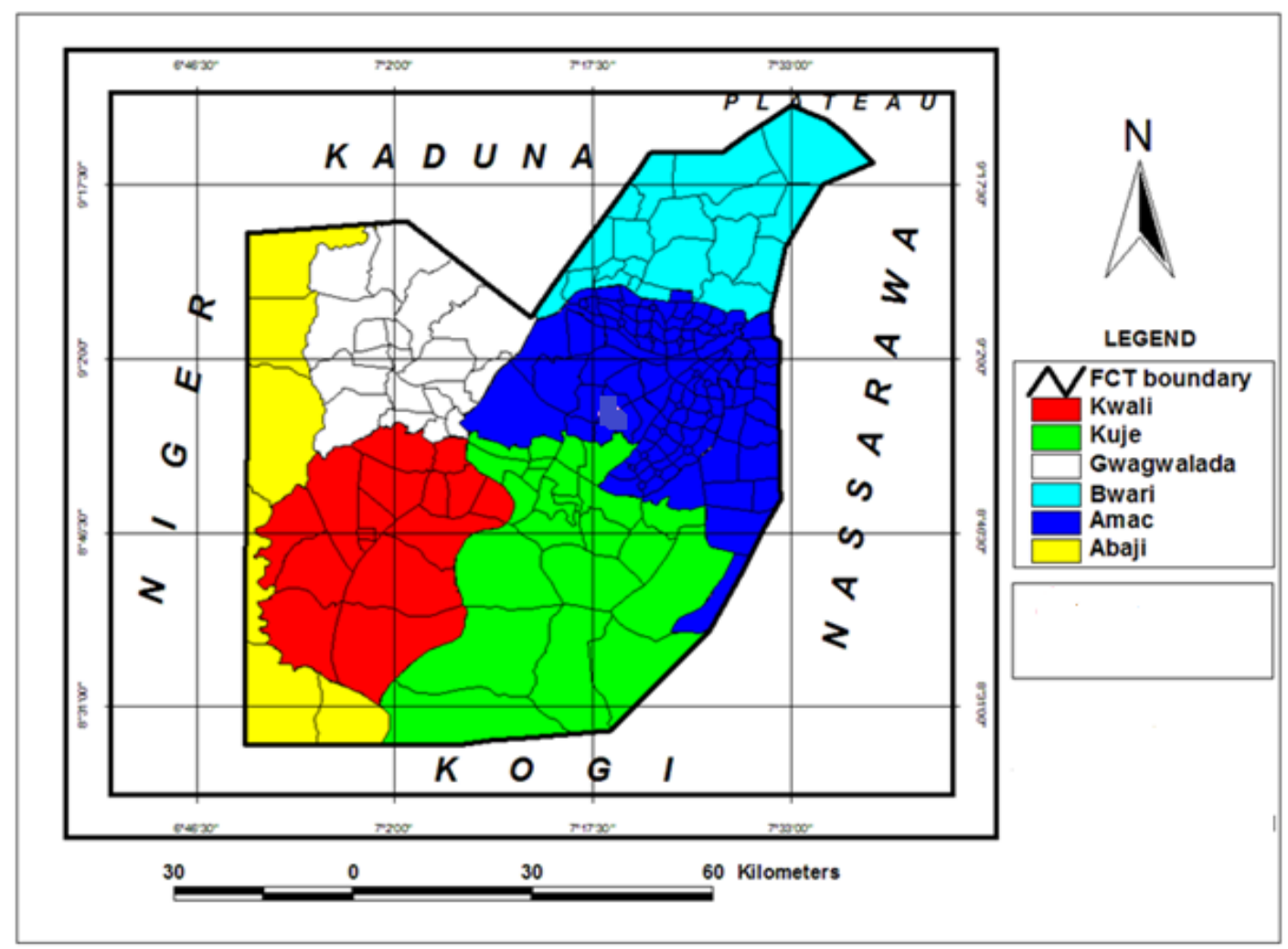

Figure 1: FCT showing the six are councils including Abuja Municipal Area Council (AMAC)

\section{METHODOLOGY}

\section{Study population}

A descriptive survey research was employed for the study. The population consisted of 277 scavengers, from 12 sites in Abuja Municipal Area Council (AMAC) of the FCT. All the scavengers used for this study belonged to the scavengers association. Two types of scavengers which exist in the city were used for the study; the itinerant pickers, who go from house to house picking useful items from bins and those scavengers that operate solely at the dumpsite, picking recyclable materials.

\section{Instrumentation}

The instrument used for this study was a structured questionnaire. The questionnaire was divided into five sections. The first section collected information on socioeconomic characteristics of scavengers and economics benefit of scavenging. The second section collected information on awareness on Covid 19, source of information and its effect on their job practices. The third section was on use of safety tools and hygiene practices of scavengers. The forth section was on occupational injuries and diseases associated with scavenging and the fifth section was on measures taken to reduce health effects of scavenging, such as routine medical checks, possible change of job etc. 
The questionnaire was interview-administered to the scavengers and where necessary the questions were translated to Hausa language. Both open-ended and closed-ended questions were included in the questionnaire. The questionnaire was administered to the scavengers in the evening at a site where the scavengers' gather after the day's work. All the participants were informed of the field research aims before the interview, this was done to facilitate the data collection process and to obtain their consent. Data collection lasted for a period of three months (August to November 2020).

\section{Data Analysis}

The statistical method used for the analysis of the data collected was descriptive statistics and the results was presented in charts and frequency tables, with the aid of Microsoft Excel and Statistical Package for Social Sciences (SPSS).

\section{RESULTS}

\section{Socio-Economic Characteristics of Scavengers}

Table 1: Socio-Economic Characteristics of Scavengers

\begin{tabular}{lll}
\hline Gender & Frequency & Percentage \\
\hline Male & 227 & 100 \\
Female & 0 & 0 \\
Total & 227 & 100 \\
Age & Frequency & Percentage \\
$15-25$ & 154 & 67.8 \\
$26-36$ & 51 & 22.4 \\
$\geq 37$ & 22 & 9.6 \\
Total & 227 & 100 \\
Educational Qualification & Frequency & Percentage \\
No formal education & 171 & 75.3 \\
Primary education & 50 & 22 \\
Secondary education & 6 & 2.6 \\
Total & 227 & 100 \\
Working hours/day & Frequency & Percentage \\
1-4 hours & 47 & 20.7 \\
5-8 hours & 118 & 51.9 \\
9 hours + & 62 & 27.3 \\
Total & 227 & 100 \\
Years of working & Frequency & Percentage \\
<1 year & 55 & 24.2 \\
1-5 years & 140 & 61.6 \\
5 years + & 32 & 14 \\
Total & 227 & 100 \\
Daily income in Naira & Frequency & Percentage \\
N1, 000-N2, 500 & 85 & 37.4 \\
N2, 500-N3, 500 & 103 & 45.3 \\
N3, 500 and above & 39 & 17.1 \\
Total & 227 & 100 \\
\hline
\end{tabular}


In Table 1, all the scavengers (100\%) were males. The table shows that $67.8 \%$ of the scavengers are between the ages of 15-25 years, $22.4 \%$ are between 26-36 years, and only $9.6 \%$ are 37 years and above. Majority of the scavengers $(75.3 \%)$ have no formal education. The study revealed that $51.9 \%$ of scavengers work for 5-8 hours per day. Over $60 \%$ of the scavengers have 1-5 years working experience. About $37.4 \%$ of the scavengers earned between N1, 000-N2, 500 per day, $45.3 \%$ earned between N2, 500-N3, 500 per day and $17.1 \%$ earned N3, 500 and above daily.

\section{Awareness of the Existence Covid 19 Pandemic}

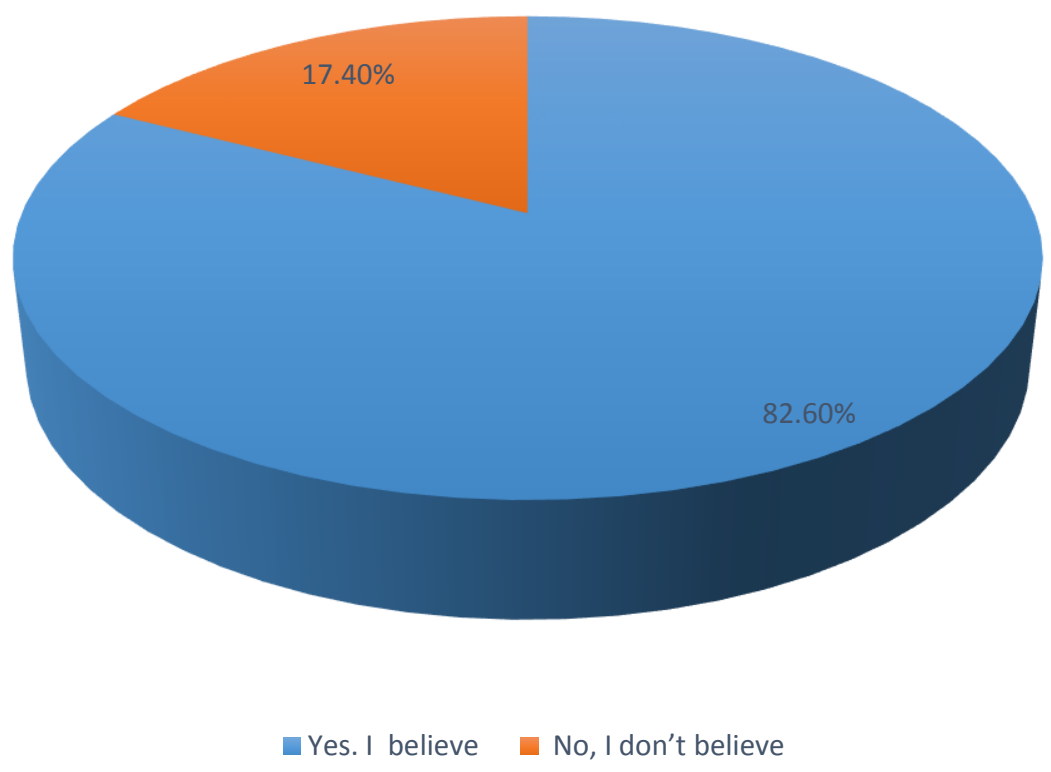

Figure 2: Awareness on the Existence Covid 19 Pandemic

Figure 2 shows that $82.6 \%$ of scavengers believe in the existence of Covid-19 pandemic in Nigeria, while $17.4 \%$ claimed that they not believe in its existence.

\section{Source of Information}

The different sources of Covid-19 information are presented in figure 3. Majority (40.8\%) of the scavengers got their information through Radio jingles. Other sources include, television jingles, posters and friends. 
American Journal of Health, Medicine and Nursing Practice

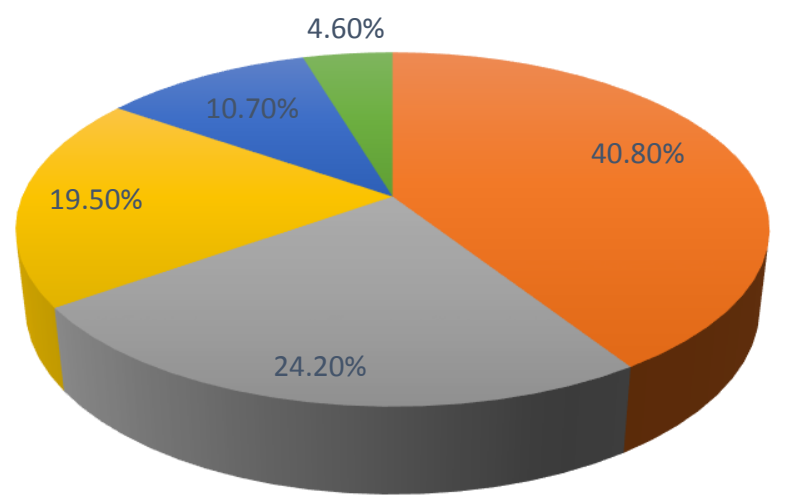

Radio jingles Television jingles $\square$ Posters $\square$ Friends $\square$ All of the above

Figure 3: Source of Information

Changes in the Practice of Scavenging since Advent of Covid 19

Figure 4 revealed that $91 \%$ of scavenger have not changed their scavenging practices, since the advent of Covid- 19. Only about $9 \%$ of them, indicated that minor changes have been made on how they scavenge for recyclables.

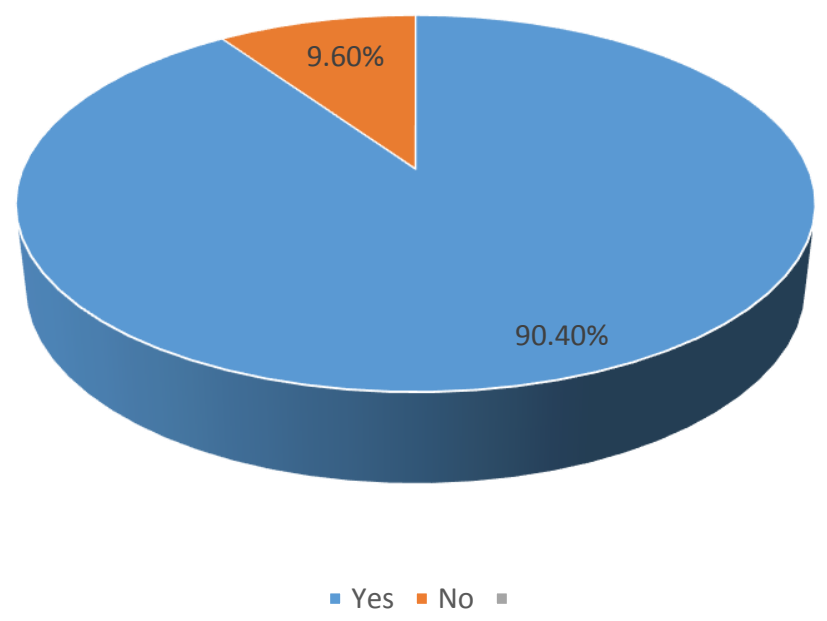

Figure 4: Changes in the Practice of Scavenging since Advent of Covid 19. Safety tools and Hygiene Practices of Scavengers. 
Figure 5 revealed, that there is poor usage for personal protective equipment and poor hygiene practices among the scavengers. About $66 \%$ of them, do not wear face mask during work, 58.4\% do no use hand gloves and $64.6 \%$ do not wear boots. The figure also revealed that $71 \%$ of scavengers do not wash their hands after work, $57 \%$ of them do not wash their clothes after work at home. Only about $41.8 \%$ of scavengers take their bath at home after work.

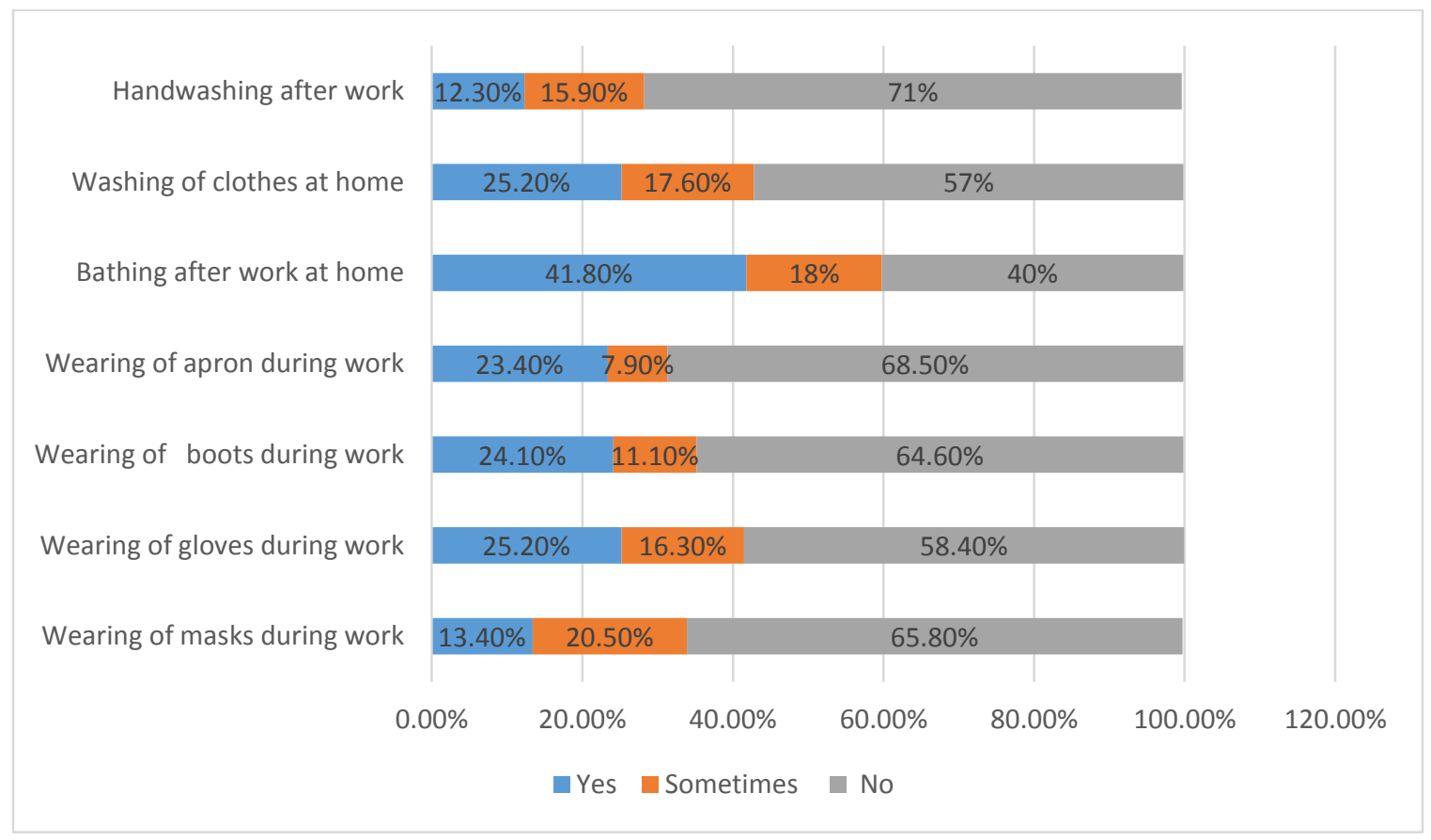

Figure 5: Safety tools and Hygiene Practices of Scavengers

\section{Occupational Injuries associated with Scavenging}

Figure 6 revealed that $90 \%$ of scavengers have sustained injuries from broken glass and sharp objects such as shaving blades and needles. About $71 \% \%$ form nails, $44.2 \%$ from fire and 22.3 $\%$ from dog bites. 
American Journal of Health, Medicine and Nursing Practice

ISSN 2520-4017 (Online)

Vol.6, Issue 1, pp 18-31, 2021

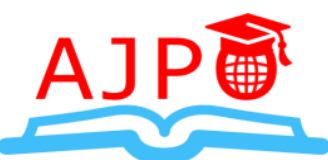

www.ajpojournals.org

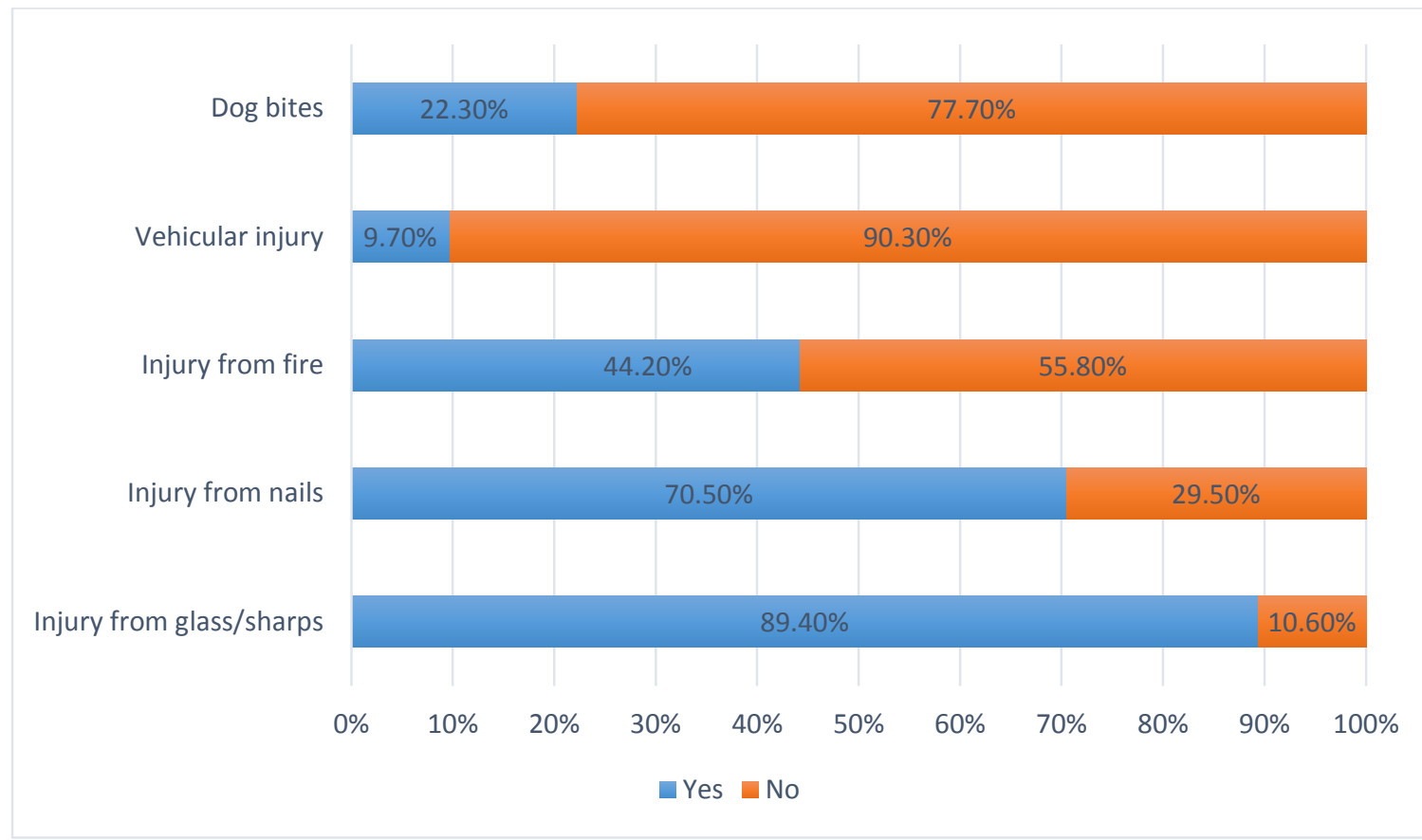

Figure 6: Occupational Injuries associated with Scavenging

Occupational Health Disease associated with Scavenging

Several type of occupational disease associated with scavenging are shown in figure 7 , these include skin rash and (83.4\%), back pain, (71.6\%), chest pain, (61.4\%), Diarrhoeal( $56.5 \%$ ), difficulty in breathing ( $51.7 \%)$, cough $(45.2 \%)$ and eye infection ( $37.9 \%)$.

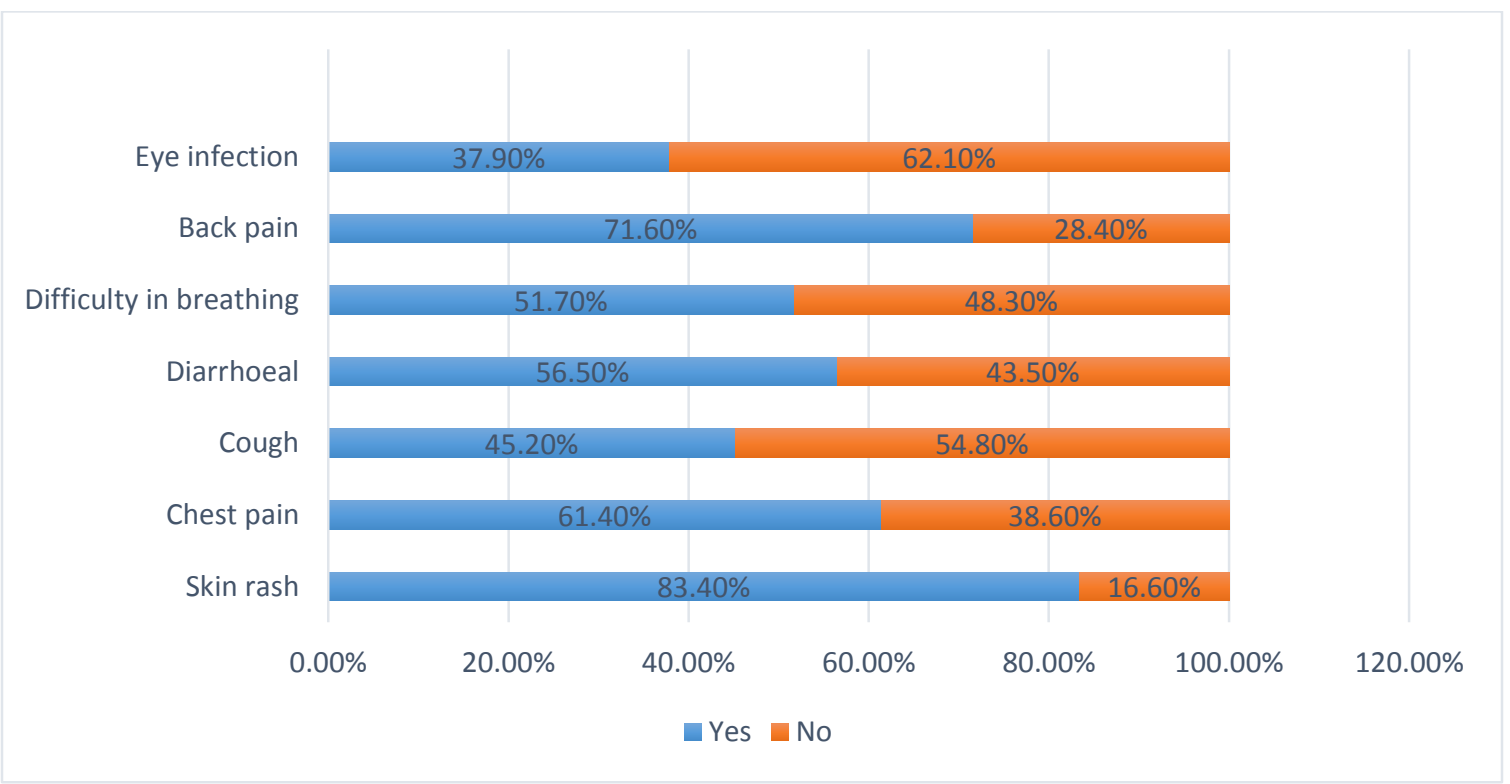

Figure 7: Occupational Health Diseases associated with Scavenging 


\section{Measures to reduce Occupational Injury and Diseases}

The figure 8 revealed the different measures that are being taken by scavengers to reduce occupational injury and disease. Only $25.6 \%$ of the scavengers visit clinics or patent medicine stores for routine check-ups. About $53.9 \%$ of them use illicit drugs (mainly marijuana and concoction of other drugs) to overcome the stress of the job. Majority (80.7\%) of the scavengers were not prepared to change their jobs, however only about $30.4 \%$ of them were prepared to purchase and use personal protective equipment as a measure to reduce occupational injury and diseases.

Readiness to purchase and use PPE

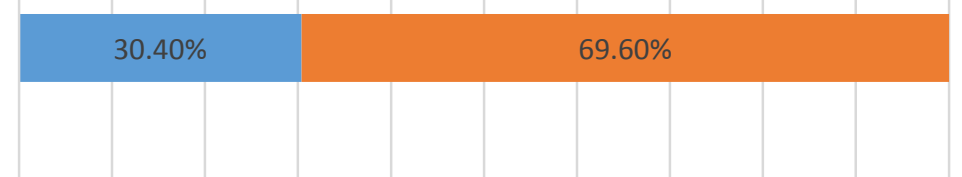

Readiness to change job
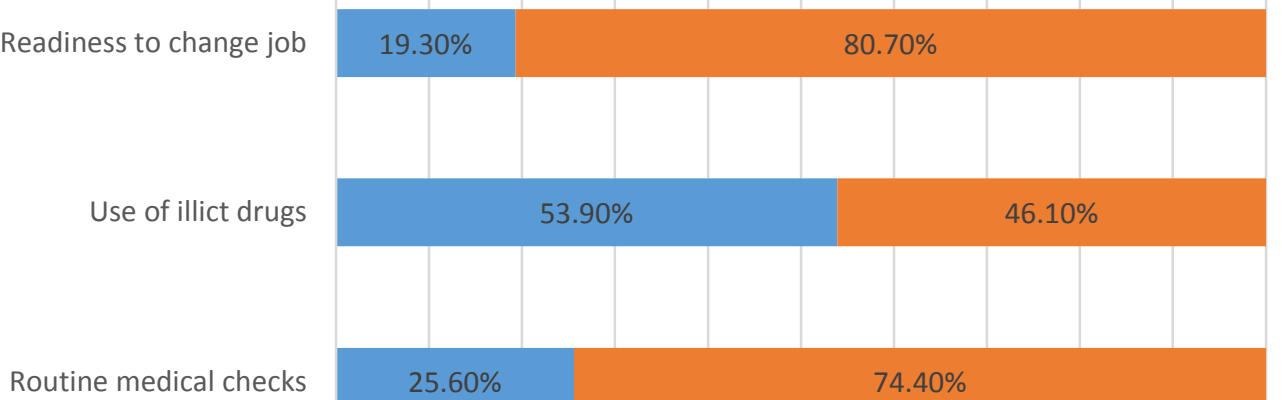

Routine medical checks

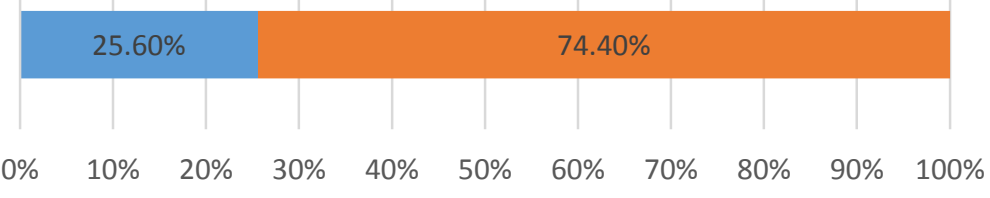

$\square$ Yes $n$ No

\section{Figure 8: Measures to reduce Occupational Injury and Diseases}

\section{Discussion}

Results of the study revealed that most of the scavengers were within the ages of (15-25 years). Many of the youth who enter the city in developing countries, in search of job are unskilled. Out of desperation to work, these youth are forced to do scavenging for survival, thus scavenging is the last resort for these desperate people (Avasthi, 2010; Pandey, 2004). Majority of them have no formal education, this is similar to the study of Elenwo (2015). According to his study, most of the scavengers did not have any formal education which is why they carried out the activities without recourse to safety and their health was at risk. All the scavengers make about N30, 000 per month, which is the minimum wage in Nigeria. This indicate that scavenging is a lucrative business, which keeps people self- employed, as well as keep the environment clean (Asibor and Edjere, 2017).

Lack of personal hygienic among scavengers may leave them prone to bacterial infection and related pathogenic diseases. Adekiya and Adeogun (2019) identified, Faecal Coliform, Faecal Steptococci, Aspergillus, Rhizopus and Salmonella among bacterial microorganisms found in the 
American Journal of Health, Medicine and Nursing Practice

ISSN 2520-4017 (Online)

Vol.6, Issue 1, pp 18-31, 2021

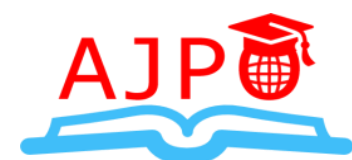

www.ajpojournals.org

dumpsites in Abuja. Scavengers were exposed to injuries at work due to lack of awareness on the significance of personal protective equipment (PPE), this is similar to the study of Nyathi, Olowoyo \& Oludare (2018) and Adeyi \& Adeyemi (2019).

Scavengers were exposed to injuries, back pain, eye infections, respiratory and dermatological infections. These findings concur with studies of Thirarattanasunthon, Siriwong, Robson \& Borjan (2012); Owusu-Sekyere (2014) and Nyathi et al (2018). The use illicit drugs (mainly marijuana and concoction of other drugs) among scavengers to overcome the stress of the job is also in line with the study carried out by Magaji and Dakyes (2011).

\section{Conclusion}

The study showed that scavenging is a lucrative business because all the scavengers' earn the Nigerian minimum wage of N30, 000 per month, so they able to meet their personal and family needs. Majority of the scavenger have no formal education, this may adversely affected their understanding on the existence of Covid 19, the importance of personal hygiene and the use of personal protective equipment (PPE). Poor personal hygiene and poor use of personal protective equipment (PPE) also contributed to them being prone to illnesses.

The study also revealed that many scavengers at one point suffered from injuries and diseases such as dog bite, injury from glass and sharps, back pain, cough, stress, diarrhoeal, skin rash, shortness of breath. Some of the scavengers also use illicit drugs for coping with stress. With the numerous problems associated with the jobs, most of the scavengers are not willing to quit the job.

\section{Recommendations}

Based on the findings, the study, recommend that scavenging be legalized, so that the government or nongovernmental organizations can help in educating the scavengers on the importance of personal hygiene and personal protective equipment in reducing occupational injuries and diseases. The National Agency for Food and Drugs Administration and Control (NAFDAC) needs to sensitize and control the use of illicit drugs among the scavenger. There should be continuous awareness program on the existence of Covid- 19 in Nigeria by government and nongovernmental organizations especially among the urban poor.

\section{REFERENCES}

Aboagye-Larbi, H., Acheampong, M. A., Kye, S. K., and Carboo, D. (2014). "The potential health hazards associated with waste scavenging in Ghana: a case study of three selected dumpsites in Tema Metropolis." International Journal of Environmental Science and Toxicology Research, vol. 2, no. 10, pp. 199-209, 2014.

Adekiya, O. A., and Adeogun, A.T. (2019). Microbiological Analysis of Solid Waste in two Open Dumpsites at Gwagwalada Area Council of Abuja. FUDMA Journal of Science, Vol.3, No.3 September 2019 pp 606-612. ISSN online 2616-1370

Adekiya, O. A., and Anokwu, J., (2020). Healthcare Waste Management among Private Healthcare Facilities in Abuja Municipal Area Council, Nigeria. Dutse Journal of Pure and Applied Sciences (DUJOPAS), 6 (3): 92-102. ISSN (Online): 2635-3490 
American Journal of Health, Medicine and Nursing Practice

ISSN 2520-4017 (Online)

Vol.6, Issue 1, pp 18-31, 2021

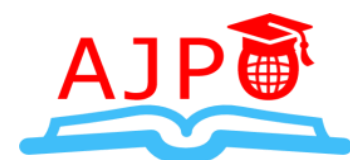

www.ajpojournals.org

Adeyi, A. A., and Adeyemi, A. M. (2019). Potential occupational health effects of municipal solid waste management in nigeria, the case of Lagos and Ibadan. Ife Journal of Science vol. 21, no. 2 (2019) https://dx.doi.org/10.4314/ijs.v21i2.15

Al-Khatib, Issam. A., Al-Sari, Majed. I., and Kontogianni, Stamatia. (2020) Assessment of Occupational Health and Safety among Scavengers in Gaza Strip, Palestine. Journal of Environmental and Public Health. Vol. 2020 https://doi.org/10.1155/2020/3780431

American Public Works Association, (1976). History of Public Works in the United States, 17761976. Baltimore: American Public Works Association;

Asibor, I., and Edjere, O., (2017). Assessment of the Activities of Scavengers and their Economic Impacts on Waste Recovery in Warri Metropolis, Delta State Nigeria. International Research Journal of Public and Environmental Health, 4(2):22-29.

Avasthi, T P. (2010). Health problems of scavengers: The case of Kathmandu metropolitan city, Nepal. The Third Pole, Vol. 8-10, PP 57-61:2010

Bakare, Wale. (2016). Solid Waste Management in Nigeria. Bioenergy Consult http://www.bioenergyconsult.com/solidwaste-nigeria. Accessed 4/12/2020

Bartone, C., (1988). The Valve in Wastes Decade Watch (September): 2-4; Medina, 1997

Blumenschine, A. R., and Cavallo. J. (1992). "Scavenging and Human Evolution. Scientific American (October): 90-96

History of Scavenging, Comparative Civilizations Review: Vol. 42: No.42, Article 4.pp 23-45

Available at: https://scholarsarchive.byu.edu/ccr/vol42/iss42/4

Ebisike, O.A., (2010). Health Care Waste Management, Principles, Regulation and Policy: A presentation to Registered Environmental Health Officers by the Registrar Environmental Health Officers Registration Council of Nigeria, Abuja FCT.

Elenwo, E.I., (2015). Assessment of the Activities of Scavengers in Obio/Akpor Local Government Areas Rivers State, Nigeria. Journal of Environmental Protection, 6:272-280.

Ezeah, C., Roberts, C.L., Phillips, P.S., Mbeng, L.O., and Nzeabibe, T.C. (2014). Evaluation of public health impact of waste scavenging in Abuja Nigeria using Q methodology. Accessed on 12Decemeber2020.

Available at:https:www.researchgate.net/publication/49939917

Federal Capital Development Authority (FCDA) (2017). The Geography of Abuja.

Available at http: //fcda.gov.ng/index.php/about-fcda/the-geography-of-abuja, Assessed on 27 November, 2020.

Furedy, C. H. (1984). Survival Strategies of the Urban Poor - Scavenging and Recuperation in Calcutta." GeoJournal (8): 129-136;

Gutberlet, J., and Baeder, A.M. (2008). Informal recycling and occupational health in Santo André, Brazil. International Journal of Environmental Health Research, vol. 18, no. 1, pp. 1-15, 2008. 
American Journal of Health, Medicine and Nursing Practice

ISSN 2520-4017 (Online)

Vol.6, Issue 1, pp 18-31, 2021

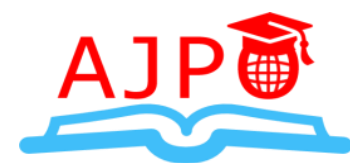

www.ajpojournals.org

International Labour Organization, (ILO) (2004). Addressing the Exploitation of Children in Scavenging (Waste Picking): A Thematic Evaluation on Action on Child Labour, Geneva, pp. 61.

Jajulwar, M. B., Saji, D. A., and Suryawanshi. S.R. (2017). An epidemiological cross sectional study to assess the socio demographic profile of rag pickers in an urban slum. Int J Community Med Public Health. Sep; 4(9):3174-3179

Kashyap, P., and Visvanathan, C. (2014). Formalization of informal recycling in low-income countries. Municipal Solid Waste Management in Asia and the Pacific Islands, pp. 41-60, Springer, Singapore, 2014.

Magaji, J.K., and Dakyes, S.P. (2011). An assessment of socio-economic impact of waste scavenging as a means of poverty alleviation in Gwagwalada Abuja. Journal Environmental Studies, vol. 6, no. 1, pp. 42-56, 2011.

Medina, M. (2010). Scrap and Trade: Scavenging Myths. United Nations University; Our world 2.0 [online] New York: UNU (Published 2010) Accessed at: http://ourworld.unu.edu/en/scavengingfrom- waste, 20-01-2021.

Nyathi, S., Olowoyo, J.O., and Oludare, A. (2018). Perception of Scavengers and Occupational Health Hazards Associated with Scavenging from a Waste Dumpsite in Pretoria, South Africa. Journal of Environmental and Public Health vol.2018 https://doi.org/10.1155/2018/9458156

Oyelola, O.T., Babatunde, A I., Abiodun, A.A., and Popoola, E.O. (2018). Occupational health hazard associated with Dumpsite scavengers and high way workers in Lagos metropolis. Journal of Environmental issues 1 (1): 13-21

Owusu-Sekyere, E. (2014). Scavenging for wealth or death? Exploring the health risk associated with waste scavenging in Kumasi. Ghana. Ghana Journal of Geography Vol. 6, 2014 Pages 63-80

Thirarattanasunthon,P., Siriwong, W., Robson, M., and Borjan, M. (2012). Health risk reduction behaviors model for scavengers exposed to solid waste in municipal dump sites in Nakhon Ratchasima Province, Thailand. Risk Management and Healthcare Policy 2012:5 97-104.

Yahaya. A. (2018). "The economic of scavenging business in Mubi metropolitan area. International Journal of Research - Granthaalayah,6(7)191-199.

https://doi.org/10.29121/granthaalayah.v6.i7.2018.1298 